\title{
DIRECT AND INDIRECT EFFECTS OF GRANDPARENT EDUCATION ON GRANDCHILDREN'S COGNITIVE DEVELOPMENT: THE ROLE OF PARENTAL COGNITIVE ABILITY
}

\author{
Markus Klein \\ University of Strathclyde, School of Education
}

\section{Michael Kühhirt}

University of Cologne, Institute of Sociology and Social Psychology

Goethe-University Frankfurt am Main, Institute of Sociology

No. $2021-06$

May 2021 


\section{NON-TECHNICAL SUMMARY}

Whether and to what extent grandparents' resources influence grandchildren's developmental and educational outcomes net of parental influence is a central question in the social stratification literature. The socioeconomic status of the grandparents can be beneficial to grandchildren's early outcomes by providing greater financial resources or direct stimulation of their cognitive development via frequent contact and interaction. The majority of studies in the grandparent literature found a direct effect of grandparent socioeconomic characteristics on grandchildren's outcomes net of parent socioeconomic characteristics.

A concern in this literature is that studies did not adequately capture parental characteristics and therefore falsely concluded that grandparent resources influence grandchildren's development. Using data from Great Britain and the 1970 British Cohort Study (BCS70), our paper contributes to this literature by accounting for a wider set of parental characteristics, including parental cognitive ability, when estimating the direct effect of grandparents' education on grandchildren's cognitive ability. We further discuss methodological issues such as varying grandparent effects across parent characteristics that we address when estimating the relative contribution of grandparent and parent resources on grandchildren's development.

Our findings show that there is only a direct effect of grandparent education on grandchildren's cognitive ability net of parental characteristics. Hence, multigenerational social reproduction appears to be mostly transmitted via parental resources. We also found that parental cognitive ability alone strongly explains the link between grandparent education and grandchildren's cognitive ability. This suggests that measuring parents' cognitive ability levels is vital for understanding intergenerational social mobility processes. 


\section{ABOUT THE AUTHORS}

Markus Klein is a Senior Lecturer in Human Development and Education Policy in the School of Education at the University of Strathclyde, UK, and Research Affiliate at the ARC Centre of Excellence for Children and Families over the Life Course. His research investigates to what extent and why family socioeconomic status shapes individuals' development and outcomes at various life course stages (from childhood over adolescence to adulthood). He is currently leading an ESRC-funded project on the mediating role of school absenteeism for social inequalities in educational attainment. Email: markus.klein@strath.ac.uk

Michael Kühhirt is a Lecturer (akad. Rat) at the Institute of Sociology and Social Psychology at the University of Cologne, Germany, and Research Affiliate at the ARC Centre of Excellence for Children and Families over the Life Course. He is currently on leave to act as Visiting Professor of Sociology (Social Stratification and Social Policy) at the Goethe University Frankfurt am Main. His research focuses on the formation and development of social inequality over the life course. He is particularly interested in the role of specific life events (e.g., childbirth) in this process as well as in social stratification in childhood and its determinants. Email: michael.kuehhirt@uni-koeln.de

\section{Acknowledgements}

The authors gratefully acknowledge the participants in the 1970 British Cohort Study (BCS70) for providing their information, the Centre for Longitudinal Studies for collecting and managing the data, and the UK Data Service for making them available.

DISCLAIMER: The content of this Working Paper does not necessarily reflect the views and opinions of the Life Course Centre. Responsibility for any information and views expressed in this Working Paper lies entirely with the author(s). 


\begin{abstract}
The multigenerational social mobility literature is mainly interested in the direct effect of grandparent resources on grandchildren's outcomes, that is, the effect not transmitted through any parent characteristics. Whereas this literature is ever-expanding, findings were inconclusive about whether there is a direct grandparent effect. Some of this heterogeneity may be due to differences in omitted variable bias at the parental level. Our paper contributes to this literature by accounting for a more extensive set of parent characteristics and exploring the mediating role of parental cognitive ability in greater detail. It further tackles methodological challenges (treatment-induced confounders, treatment-mediator interaction) in assessing any direct influences of grandparents by estimating the Natural Direct Effect (NDE) of grandparent education with a regression-with-residuals approach. Using the 1970 British Cohort Study (BCS70), our results show that the direct effect of grandparent education on grandchildren's verbal and numerical ability is small and statistically non-significant. Estimating the Natural Indirect Effect (NIE), cognitive ability alone can account for more than two-third (numerical ability) or half (verbal ability) of the grandparent effect. These findings stress the importance of cognitive ability for intergenerational social mobility processes. Implications for future research are discussed.
\end{abstract}

Keywords: Social stratification, social mobility, multigenerational mobility, grandparent effects, cognitive development.

Suggested citation: Klein, M. \& Kühhirt, M. (2021). 'Direct and Indirect Effects of Grandparent Education on Grandchildren's Cognitive Development: The Role of Parental Cognitive Ability', Life Course Centre Working Paper Series, 2021-06. Institute for Social Science Research, The University of Queensland. 


\section{Introduction}

Multigenerational mobility processes have increasingly become of interest to social stratification researchers, partly as a reaction to Mare's (2011) call to overcome the "two-generation paradigm" that dominated the literature for decades. In this literature, the main interest is whether grandparents' (G1) education or class has a direct impact on grandchildren's (G3) outcomes (e.g., cognitive development, educational attainment) net of parental (G2) characteristics. A recent systematic review on grandparent effects on educational outcomes included 69 analyses from 40 publications (Anderson, Sheppard, \& Monden, 2018). Although the literature has steadily expanded over the last decade (e.g., Engzell, Mood, \& Jonsson, 2020; Erola, Kilpi-Jakonen, Prix, \& Lehti, 2018; Fiel, 2019; Lehti et al., 2018; Liu, 2018; Sheppard \& Monden, 2018; Zhang \& Li, 2018), findings are inconclusive whether there is a direct effect of grandparent socioeconomic characteristics on grandchildren's educational outcomes. In their review, Anderson et al. (2018) concluded that 58 percent of studies found a statistically significant association between G1 socioeconomic characteristics and G3 educational outcomes net of G2 characteristics. They estimated that, on average, 30 percent of the G1-G3 association remains once G2 information is included in the modeling.

A primary concern when estimating the direct effect of G1 socio-economic characteristics on G3 outcomes is omitted variable bias on the G2 level. Various pathways through which grandparent resources may influence grandchildren's outcomes via parents exist, and failing to condition on important G2 characteristics may bias the direct effect of G1 socio-economic characteristics. However, Anderson et al. (2018) conclude that studies conditioning on a larger number of parental variables did not attenuate the G1 effect more considerably than studies with a limited number. They argue that this provides some reassurance in the robustness of direct effects of $\mathrm{G} 1$ socio-economic characteristics on $\mathrm{G} 3$ educational outcomes. By contrast, Engzell et al. (2020) showed that the size of the direct grandparent effect significantly varies with measurement error on the G2 level and depends on studies' sample and specification characteristics. Hence, it is not surprising that findings are so varied, and heterogeneity in operationalizing parental measures and modeling strategies complicate the interpretation of findings on grandparent effects.

In this paper, we aim to stress the role of parental cognitive ability in multigenerational mobility processes. There is abundant evidence for a strong relationship between parents' socioeconomic status and children's cognitive development (e.g., Connelly \& Gayle, 2019; Dearden, Sibieta, \& Sylva, 2011; Sullivan, Ketende, \& Joshi, 2013) and intergenerational reproduction of cognitive ability (Crawford, Goodman, \& 
Joyce, 2011; de Coulon, Meschi, \& Vignoles, 2011). Given these associations, it is reasonable to assume that parental cognitive ability is an important mediator of the relationship between $\mathrm{G} 1$ resources and G3 outcomes. However, the grandparent literature has largely ignored the role of cognitive ability at the G2 level (for exceptions, see Hällsten \& Pfeffer, 2017; Stuhler, 2012). Accounting for parental cognitive ability alone may significantly reduce the direct effect of grandparent resources on grandchildren's educational outcomes (Engzell et al., 2020).

While existing studies on multigenerational reproduction, including the recent systematic review, discuss the issue of omitted variable bias on the G2 level, they have largely ignored other fundamental methodological issues (for exceptions, see Hällsten \& Pfeffer, 2017; Song, 2016). In a recent critique of this literature, Breen (2018) highlighted that identifying the direct effect of G1 socio-economic characteristics on $\mathrm{G} 3$ outcomes is notoriously difficult as unobserved factors (U) causing $\mathrm{G} 2$ characteristics and G3 outcomes may lead to estimates of a direct G1 effect that suffer from collider bias. That is, conditioning on $\mathrm{G} 2$ characteristics potentially opens up non-causal paths from $\mathrm{G} 1$ to $\mathrm{G} 2$ to $U$ to $\mathrm{G} 3$, leading to biased estimates of direct effect.

Researchers can partly overcome this problem by controlling for observable mediator-outcome confounders in their analysis. However, this strategy may be problematic if G1 characteristics are causally linked to post-treatment confounders of the association between G2 characteristics and G3 outcomes. In this scenario, avoiding collider bias by adjusting for treatment-induced mediator-outcome confounders in the analysis may result in overcontrol bias and biased estimates of the direct effect of G1 socio-economic characteristics on G3 outcomes (Acharya, Blackwell, \& Sen, 2016). These issues imply that it is not only relevant to adjust for a comprehensive set of $\mathrm{G} 2$ variables, but it also matters how we adjust for them.

In this paper, we estimate the direct and indirect effect of G1 education on G3 cognitive development and advance the literature on multigenerational social reproduction in several meaningful ways. First, in our analyses, we go beyond standard socioeconomic measures and condition on a large set of G2 characteristics, including parents' cognitive ability. Hence, we can address some of the concerns around omitted variable bias on the G2 level. Second, we use a novel statistical technique, causal mediation analysis using regression-with-residuals (Wodtke \& Zhou, 2020), to deal with collider and overcontrol bias in the study of multigenerational mobility. Causal mediation analysis further allows us to estimate direct and indirect effects in the presence of interactions between G1 (treatment) and G2 (mediator) characteristics (VanderWeele, 2015). Using data from the British Cohort Study 1970 (BCS70), we exploit 
that the BCS70 randomly selected half of the cohort members who lived with their natural or adopted children at the age of 34 for additional child assessments, including their cognitive ability. Other than in most previous research using G1 information provided by parents, this prospective design allows us to use G1 characteristics provided by grandparents when parents were young. Hence, measurement error and attenuation bias on the G1 level should be limited (Anderson et al., 2018).

\section{Grandparents' education and grandchildren's cognitive development}

A central hypothesis in the grandparent literature is that grandparents can directly shape their grandchildren's development via frequent contact and interaction (Dunifon, Near, \& Ziol-Guest, 2018). Grandparents' education may influence grandchildren's cognitive ability in the same way as parental education (Guryan, Hurst, \& Kearney, 2008; Kalil, Ryan, \& Corey, 2012; Sayer, Gauthier, \& Furstenberg, 2004). Highly educated grandparents may spend more time with their grandchildren or spend more time in educational activities (e.g., reading to grandchildren, visiting museums, helping with homework) that stimulate their cognitive development than grandparents who are less educated. Grandparents' education may also positively influence grandchildren's educational aspirations and their attitudes towards learning.

This contact-based mechanism may only operate if grandparents are alive and live close to their children. Hence, grandparent education should only matter for grandchildren's cognitive development if grandparents have the opportunity to spend time with their children and use their resources in the learning and socialization of their grandchildren. Many studies that tested this interaction between G1 resources and measures of G1 proximity were unable to find any evidence of differences in the G1 effect across G1 availability (e.g., Bol \& Kalmijn, 2016; Braun \& Stuhler, 2017; Ferguson \& Ready, 2011; Sheppard \& Monden, 2018).

Grandparents may also transfer financial resources in their lifetime or after death to their parents (Hochguertel \& Ohlsson, 2009). They can use these additional resources to improve children's living standards or buy toys, books, tuition, or high-quality early childcare, to stimulate their children's learning (Linver, Brooks-Gunn, \& Kohen, 2002; Yeung, Linver, \& Brooks-gunn, 2002). Since grandparent education is strongly associated with wages, higher educated grandparents are more likely to support their children financially. Grandparents also have an impact on grandchildren through their social networks. The more educated grandparents are, the more beneficial their social networks may be in stimulating 
grandchildren's cognitive development. Parents whose parents have higher educational qualifications may rely on these networks irrespective of whether grandparents are alive or dead.

The effect of grandparent education on grandchildren's cognitive development may depend on the magnitude of parental resources (Anderson et al., 2018). The 'compensation hypothesis' suggests that the direct effect of $\mathrm{G} 1$ resources on $\mathrm{G} 3$ outcomes is smaller when $\mathrm{G} 2$ cognitive ability is high. This is because parents may not harness additional grandparent resources as much as they would if their cognitive resources were low. Grandparents may also abstain from intervening in family life and parenting if their children have sufficient abilities to raise their grandchildren. Hence, grandparents may only activate their resources - be it financially, socially, or via stimulating interactions with their grandchildren - if they need to compensate for their children's lack of cognitive ability (Bengtson, 2001).

By contrast, Chiang and Park (2015) postulate the 'augmentation hypothesis' suggesting that only higher educated parents can activate grandparent resources. Lower educated parents may have limited knowledge and information on learning and cannot exploit grandparent resources that are stimulating for their children's development. Although empirical tests of the moderating role of $\mathrm{G} 2$ resources in the association between $\mathrm{G} 1$ resources and G3 outcomes are relatively sparse, the literature provides more evidence for the 'compensation hypothesis' (for an overview, see Anderson et al., 2018; Braun \& Stuhler, 2017; Deindl \& Tieben, 2016; Jaeger, 2012).

\section{Some methodological issues}

The standard approach to investigating whether grandparents directly affect their grandchildren has been to estimate the association between their characteristics net of parental factors. A key challenge in this literature is to specify the relevant parental variables and obtain reliable measures (Engzell et al., 2020). However, finding and accurately accounting for the relevant parental variables is not sufficient. To identify direct grandparent effects, the analyst also needs to assume that there is no (unmeasured) confounding of the association between grandparent and child characteristics and parent and child characteristics. The majority of empirical studies did not readily address this concern (Breen, 2018). In the current study, we highlight two additional challenges for studies of direct grandparent effects, (1) confounders that are themselves affected by the grandparent characteristics (treatment-induced confounding) and (2) interactions between grandparent and parent characteristics. 
To fix ideas, consider Figure 1, which displays a typical mediation scenario where grandparent education (X) affects parental characteristics (M), which in turn affects children's cognitive ability (Y). $\mathrm{X}$ is also hypothesized to affect $Y$ directly, the causal relation of key interest in the grandparent effects literature. In this scenario, both defining and identifying the direct and indirect effect of grandparent education is straightforward. The direct effect (net of parental characteristics) is composed only of the arrow from $X$ to $\mathrm{Y}$. It is identified by the association between $\mathrm{X}$ and $\mathrm{Y}$ conditional on $\mathrm{M}$ and baseline confounders $\mathrm{Z}$. The indirect effect is composed of the two effects $X->M$ and $M->Y$. The first effect is identified by the association between $\mathrm{X}$ and $\mathrm{M}$ conditional on $\mathrm{Z}$, the second effect by the association between $\mathrm{M}$ and $\mathrm{Y}$ conditional on $\mathrm{X}$ and $\mathrm{Z}$.

Figure 1. Causal relations between grandparent education $(X)$, parental characteristics $(\mathrm{M})$ and child cognitive ability $(\mathrm{Y})$

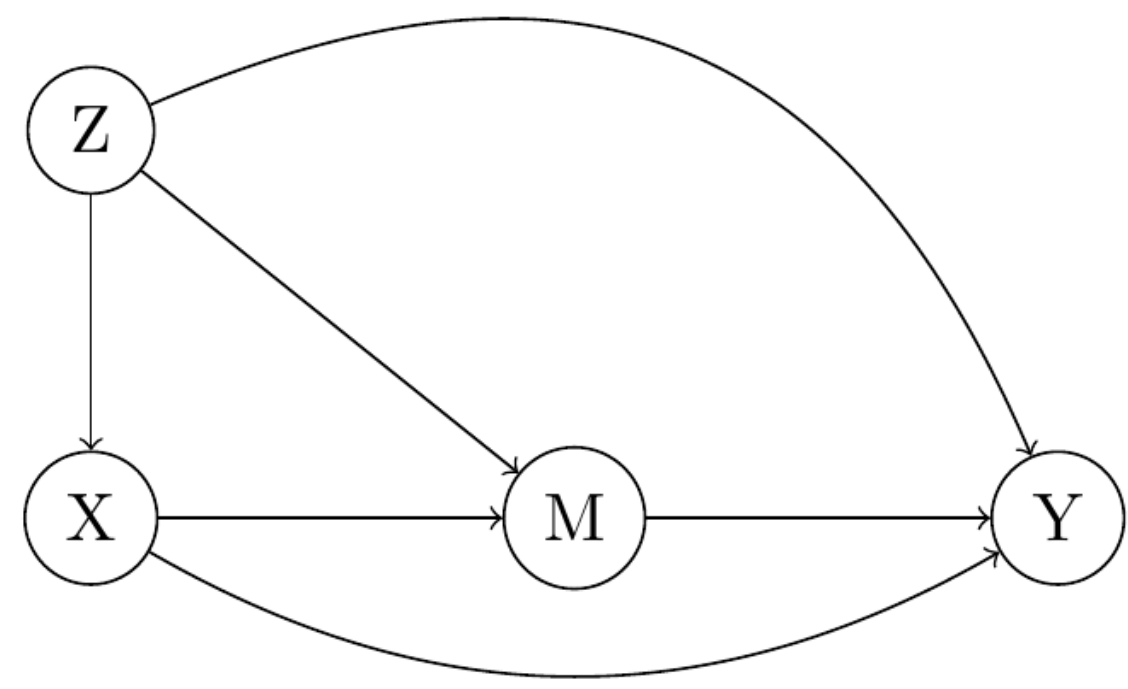

However, assuming such a multigenerational mobility scenario seems implausible (see Figure 2). There are likely to be additional grandparent characteristics (depicted as L in Figure 2), for example, grandparent wealth. These G1 characteristics are potentially affected by our exposure of interest, grandparent education $(\mathrm{X})$, and affect some or all parental characteristics $\mathrm{M}$ and child outcome $\mathrm{Y}$. This more realistic scenario comes with several challenges for identifying the direct effect of $X$ (net of all parental characteristics) and the indirect effect of $\mathrm{X}$ through one or more $\mathrm{M}$.

Identifying the direct effect of $\mathrm{X}$ requires us to condition on all parental characteristics. Doing so in the scenario displayed in Figure 2, however, would not provide an association that identifies the direct effect 
because $\mathrm{M}$ are colliders on a path from $\mathrm{X}$ to $\mathrm{Y}$. This is the result of other grandparent characteristics at the G1 level ( $Z$ and $L$ in Figure 2) affecting both parental characteristics (M) and grandchild outcome $Y$. Any association between $\mathrm{X}$ and $\mathrm{Y}$ conditional on $\mathrm{M}$ may mix the direct effect of interest and noncausal associations due to conditioning on a collider. At first glance, the direct effect may be recovered by additionally conditioning on these other $\mathrm{G} 1$ characteristics, $\mathrm{Z}$ and L, which would erase the noncausal association created by conditioning on a collider. However, upon noting that the effect of $\mathrm{X}$ not mediated by $G 2$ characteristics in this scenario includes $X->L->Y$ in addition to $X->Y$, it becomes evident that conditioning on $L$ will also not recover the effect of interest. Conditioning on $L$ will instead lead to overcontrol bias as it would eliminate parts of the association resulting from the effect of interest (i.e., X$>L->Y$.

Moreover, potential interactions between $\mathrm{X}$ and $\mathrm{M}$ (as discussed in the theory section) result in conceptual difficulties in defining direct and indirect effects. More specifically, an interaction implies there are multiple direct and indirect effects of $\mathrm{X}$, one for each value of $\mathrm{M}$. If a treatment-mediator interaction exists and is not accounted for, this can also bias the estimates for direct and indirect effects.

In sum, to address the challenges of identifying the direct and indirect effects of grandparent education, we need to find a set of parental variables $\mathrm{M}$ that blocks all indirect paths through parental characteristics. We also need to find a set of grandparent variables for which conditioning would eliminate bias from conditioning on the parental collider variables without blocking any of the paths from $\mathrm{X}$ to $\mathrm{Y}$. We rely on specific statistical methods that account for these covariates without blocking part of the direct effect and allow for effect decomposition in the presence of treatment-induced confounders. Below we provide a precise definition of the effects of interest in our analysis and describe the methods used for estimation. 
Figure 2. Causal relations between grandparent education $(X)$, parental characteristics $(\mathrm{M})$ and child cognitive ability $(\mathrm{Y})$ in the presence of treatmentinduced mediator-outcome confounders (L)

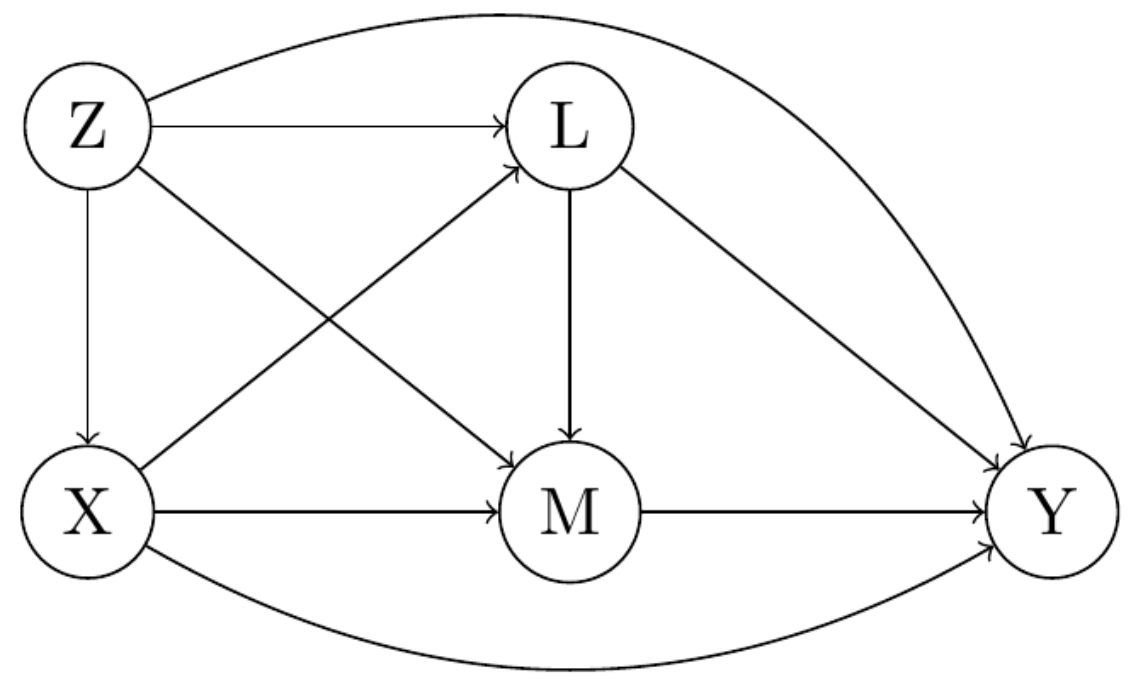

\section{Methods and data}

\section{Analytic strategy}

The target quantity in the bulk of the literature on grandparent effects is colloquially referred to as the direct effect of the respective grandparent characteristic, that is, the effect that is not transmitted through any parent characteristics. However, once we allow for interactions between grandparent and parent characteristics, there is a host of different direct effects depending on the values of the parent characteristics. Each of these effects has different theoretical implications. For this analysis, we focus on the natural direct effect (NDE), or more specifically, its randomized intervention analogue (NDE $\left.{ }^{R}\right)$ (VanderWeele, 2015). This direct effect answers whether after deactivating any influence through $M, X$ still affects $Y$, the central question in the grandparent effects literature. It represents a population average of the direct effect over the levels of the mediator. Formally, it is defined as the expected difference in the child outcome $Y$ if all children in the population were exposed to grandparents with a 'degree' $(X=1)$ rather than to grandparents with 'no degree' $(X=0)$ while fixing parent characteristics $M$ at value $G^{x^{\prime} \mid z}$, randomly drawn from the distribution under 'no degree' among those with baseline confounders Z: 


$$
N D E^{R}=E\left(Y^{x G^{x^{\prime} \mid Z}}\right)-E\left(Y^{x \prime G^{x^{\prime} \mid Z}}\right)
$$

The definition is based on potential outcomes, $Y^{\mathrm{ym}}$, which capture the outcome had a child been exposed to values of $X$ and $M$. The NDE ${ }^{R}$ can be identified under the assumptions outlined above that the sets of confounders $Z$ and $L$ are measured and can thus be adjusted for.

To estimate the association that identifies the NDER , we use a "regression-with-residuals" approach (Zhou \& Wodtke, 2019; Wodtke \& Zhou, 2020). The method is based on the following conditional mean model of the child outcomes given the set of baseline confounders $Z$, grandparent education $X$, the set of treatment-induced confounders $L$, and the set of parent characteristics $M$ :

$$
E(Y \mid Z, X, L, M)=\beta_{0}+\beta_{1}^{T} Z^{\perp}+\beta_{2} X+\beta_{3}^{T} L^{\perp}+\beta_{4}^{T} M+\beta_{5}^{T} X M,
$$

where $Z^{\perp}$ refers to a vector of mean-centered baseline confounders and $L^{\perp}$ to a vector of residualized treatment-induced confounders. The latter can be obtained by a set of models estimating the conditional mean for each treatment-induced confounder given grandparent education and mean-centered baseline confounders. Since the residualized treatment-induced confounders $\left(L^{\perp}\right)$ are independent of $\mathrm{X}$ and $\mathrm{Z}$, their adjustment does not induce over-control bias (see Figure 3).

We also need a set of models for the parent characteristics given baseline confounders and grandparent education. For continuous characteristics a conditional mean model is used that can be estimated by OLS regression:

$$
E(M \mid Z, X)=\theta_{0}+\theta_{1}^{T} Z^{\perp}+\theta_{2} X
$$

For categorical mediators, we use probability models that can be estimated using logistic regression. If all relevant confounders are included and all models (equations 2 and 3 and models for the treatmentinduced confounders) are correctly specified in terms of functional form, the NDE $^{R}$ is identified by a combination of parameters from equation 2 and equation 3 :

$$
N D E_{R W R}^{R}=\beta_{2}+\beta_{5}^{T} \theta_{0}
$$


Concrete estimates are obtained by fitting the required models using (generalized) linear models and computing the respective term in equation 4 based on the fitted models. Standard errors are computed using the non-parametric bootstrap.

Our second goal is to assess the role of parental cognitive ability in more detail. We do this by quantifying the randomized intervention analogue of the natural indirect effect $\left(\mathrm{NIE}^{\mathrm{R}}\right)$ of grandparent education through parent cognitive ability on child outcomes, which is formally defined as follows:

$$
N I E^{R}=E\left(Y^{x G^{x \mid Z}}\right)-E\left(Y^{x G^{x^{\prime} \mid Z}}\right) .
$$

It captures the average difference in the child outcomes $Y$ if all children in the population were exposed to grandparents with a 'degree' $(X=1)$ and then were exposed to a value of $M$ randomly drawn from the distribution under 'degree' rather than under 'no degree'. In other words, it represents the effect of grandparent education once all pathways not running through parent cognitive ability are disabled. Subsequently, we can calculate the proportion of the total effect of grandparent education mediated by parent cognitive ability alone. Provided the assumptions already mentioned above hold, the $\mathrm{NIE}^{\mathrm{R}}$ is equal to

$$
N I E_{R W R}^{R}=\theta_{2}\left(\beta_{4}+\beta_{5}\right),
$$

once the model in equation 3 does not include any parent characteristics affected by parent cognitive ability. 
Figure 3. Causal relations between grandparent education $(X)$, parental cognitive ability $(\mathrm{M})$ and child cognitive ability $(\mathrm{Y})$ in the presence of residualized post-treatment mediator-outcome confounders $\left(L^{\perp}\right)$

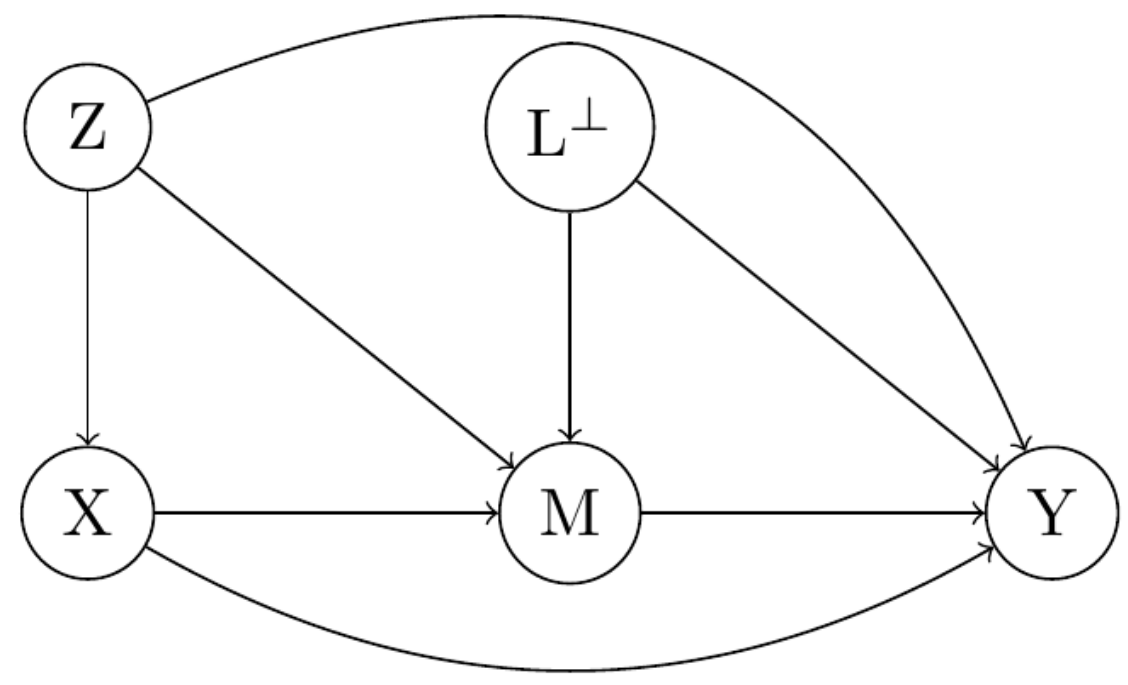

Data

We draw on longitudinal information from three generations using the 1970 British Cohort Study (BCS70). The BCS70 followed the lives of people born in England, Scotland, and Wales in a single week of 1970 (Elliott \& Shepherd, 2006). Data were collected at birth, age five, 10, 16, 26, and four-year intervals from 30 onwards. Crucially, the BCS70 randomly selected half of the cohort members who lived with their natural and adopted children at the age of $34(n=2,846)$ for additional questions and assessments with their children, including numerical and verbal ability $(n=5,207)$. While all parents were of the same age, children between three and sixteen were interviewed and tested with age-specific assessments. Therefore, our analysis is restricted to children born to parents of the 1970 cohort in 2001 or earlier ( $n=$ $3,499)$. The prospective design allows us to use information on socioeconomic resources among G1 (parents' cohort members), G2 (cohort members), and G3's scores in cognitive assessments. Grandparents provided information on their socioeconomic characteristics in wave three when parents were aged 10 (Butler and Bynner 2016). Parental characteristics are taken from the third wave and the first wave (Chamberlain, 2013) when measuring early childhood indicators and from wave seven (age 34, University of London, 2016) when measuring their socioeconomic resources. Our analytical sample 
excluded grandparents with an ethnic background as small case numbers $(n=98)$ prevent us from explicitly adjusting for ethnicity in our models. Listwise deletion leaves us with complete cases for 1,898 $(1,884)$ children from $1,120(1,109)$ families for the analysis on verbal ability (numerical ability).

\section{Variables}

Our outcome of interest is the child's cognitive ability (depicted as G3 in Figure 2) using the British Ability Scales (BAS) Second Edition, a widely used battery of individually administered tests of cognitive abilities and educational achievements for children between the ages of 2.5 and 17 years (Elliott, Smith, \& McCulloch, 1996; Elliott, Smith, \& McCulloch, 1997). Children aged three to five were tested on Naming Vocabulary, while children aged six to 16 were tested on Word Reading. Numerical ability was assessed with Early Number Concepts among young children and an assessment of Number Skills among older children. For all tests, we use test scores that correct for differences in item difficulty. 
Table 1. Summary Statistics $(N=1,898)$

\begin{tabular}{|c|c|c|c|c|}
\hline & Mean/Proportion & SD & Min & Max \\
\hline \multicolumn{5}{|l|}{ Outcome (Y) } \\
\hline Verbal ability & 2.20 & 21.43 & -76.99 & 81.53 \\
\hline Numerical ability* & 1.94 & 16.76 & -61.74 & 62.25 \\
\hline \multicolumn{5}{|l|}{ Treatment $(X)$} \\
\hline Grandparent education: degree or higher & 0.14 & & 0.00 & 1.00 \\
\hline \multicolumn{5}{|l|}{ Parental characteristics (M) } \\
\hline \multicolumn{5}{|l|}{ Parental education } \\
\hline None & 0.28 & & 0.00 & 1.00 \\
\hline Lower secondary schooling: O-level or equiv. & 0.45 & & 0.00 & 1.00 \\
\hline Upper secondary schooling: A-level or equiv. & 0.06 & & 0.00 & 1.00 \\
\hline Degree or higher & 0.22 & & 0.00 & 1.00 \\
\hline \multicolumn{5}{|l|}{ Parental class } \\
\hline Higher managerial and professional occupations & 0.06 & & 0.00 & 1.00 \\
\hline Lower managerial and professional occupations & 0.23 & & 0.00 & 1.00 \\
\hline Intermediate occupations & 0.14 & & 0.00 & 1.00 \\
\hline Small employers and account workers & 0.08 & & 0.00 & 1.00 \\
\hline Lower supervisory and technical occupations & 0.10 & & 0.00 & 1.00 \\
\hline Semi-routine occupations & 0.14 & & 0.00 & 1.00 \\
\hline Routine occupations & 0.10 & & 0.00 & 1.00 \\
\hline Never worked and long-term unemployed & 0.15 & & 0.00 & 1.00 \\
\hline Parental savings and investments in $f$ & 6045.18 & 21683.30 & 0.00 & 310000.00 \\
\hline Parental income (weekly) in $f$ & 682.71 & 1441.16 & 14.96 & 39805.30 \\
\hline \multicolumn{5}{|l|}{ Parental siblings } \\
\hline Zero & 0.09 & & 0.00 & 1.00 \\
\hline One & 0.45 & & 0.00 & 1.00 \\
\hline Two & 0.31 & & 0.00 & 1.00 \\
\hline Three & 0.10 & & 0.00 & 1.00 \\
\hline More than four & 0.06 & & 0.00 & 1.00 \\
\hline \multicolumn{5}{|l|}{ Partner resources } \\
\hline No partner & 0.11 & & 0.00 & 1.00 \\
\hline $\begin{array}{l}\text { Partner left education age } 16 / \text { not employed in } \\
\text { manag. or prof. occupations }\end{array}$ & 0.45 & & 0.00 & 1.00 \\
\hline $\begin{array}{l}\text { Partner left education age } 16 / \text { employed in } \\
\text { manag. or prof. occupations }\end{array}$ & 0.11 & & 0.00 & 1.00 \\
\hline
\end{tabular}




\begin{tabular}{|c|c|c|c|c|}
\hline $\begin{array}{l}\text { Partner continued education after age } 16 / \text { not } \\
\text { employed in manag. or prof. occupations }\end{array}$ & 0.18 & & 0.00 & 1.00 \\
\hline $\begin{array}{l}\text { Partner continued education after age 16/ } \\
\text { employed in manag. or prof. occupations }\end{array}$ & 0.13 & & 0.00 & 1.00 \\
\hline \multicolumn{5}{|l|}{ Parental health } \\
\hline Excellent & 0.33 & & 0.00 & 1.00 \\
\hline Good & 0.47 & & 0.00 & 1.00 \\
\hline Fair & 0.14 & & 0.00 & 1.00 \\
\hline Poor/Very Poor & 0.06 & & 0.00 & 1.00 \\
\hline Parental cognitive ability & -0.00 & 0.89 & -3.12 & 2.85 \\
\hline Parental birthweight in grams & 3331.57 & 531.72 & 1361.00 & 5448.00 \\
\hline \multicolumn{5}{|l|}{ Baseline confounders (Z) } \\
\hline \multicolumn{5}{|l|}{ Region } \\
\hline North & 0.07 & & 0.00 & 1.00 \\
\hline York and Humberside & 0.10 & & 0.00 & 1.00 \\
\hline East Midlands & 0.07 & & 0.00 & 1.00 \\
\hline East Anglia & 0.04 & & 0.00 & 1.00 \\
\hline South East & 0.23 & & 0.00 & 1.00 \\
\hline South West & 0.08 & & 0.00 & 1.00 \\
\hline West Midlands & 0.10 & & 0.00 & 1.00 \\
\hline North West & 0.12 & & 0.00 & 1.00 \\
\hline Wales & 0.07 & & 0.00 & 1.00 \\
\hline Scotland & 0.11 & & 0.00 & 1.00 \\
\hline \multicolumn{5}{|l|}{ Treatment-induced $M-Y$ confounders ( $L$ ) } \\
\hline \multicolumn{5}{|l|}{ Grandparent class } \\
\hline Service class & 0.26 & & 0.00 & 1.00 \\
\hline Intermediate class & 0.23 & & 0.00 & 1.00 \\
\hline Working class & 0.52 & & 0.00 & 1.00 \\
\hline Grandparent in poor health: yes & 0.23 & & 0.00 & 1.00 \\
\hline Grandparent homeownership: yes & 0.59 & & 0.00 & 1.00 \\
\hline Grandparent income (weekly) in $f$ & 126.54 & 57.87 & 17.50 & 275.00 \\
\hline
\end{tabular}

Source: British Cohort Study (BCS70); Note: * Summary statistics for numerical ability based on N =1,884. 
Age-normalizing verbal and numerical test scores in these data is not straightforward given that the child's age is collinear with the parent's age at the child's birth. This is problematic if parents' age is also correlated with other parental characteristics that are influenced by G1 characteristics and determine G3 cognitive ability. Age-normalizing would, therefore, partially adjust for some of the G2 characteristics that we wish to consider as mediators in our outcome model. To avoid this problem, we follow the approach by Crawford et al. (2011), in which we normalize test scores by using the residuals from a regression of test scores on age and all other variables used in the outcome models.

Our treatment is grandparents' education (depicted as X in Figure 2), which we operationalize as a binary indicator differentiating between at least one of cohort members' parents with a degree or higher vs. no grandparent with a degree or higher.

Our mediators are parental characteristics (depicted as $\mathrm{M}$ in Figure 2) of the cohort member measuring standard socioeconomic dimensions such as parental education, class, income, and wealth. Parental education and parental class are measured with the cohort member's information. Parental education is operationalized using four categories: 1) none, 2) lower secondary schooling (O-level or equiv.), 3) upper secondary schooling (A-level or equiv.), and 4) degree or higher. Parental class is measured using the 8category analytical version of the National Socio-Economic Classification (NS-SEC): 1) higher managerial and professional occupations, 2) lower managerial and professional occupations, 3) intermediate occupations, 4) small employers and own account workers, 5) lower supervisory and technical occupations, 6) semi-routine occupations, 7) routine occupations, and 8) never worked or long-term unemployed. Parental income is derived from information on the cohort member's and partner's total take-home-pay after all deductions (e.g., tax, national insurance, union dues, or pension) and income sources other than work. We approximate parental wealth with indicators of homeownership and savings, and investments. For homeownership, we differentiate between owning a home (outright or mortgage) and renting a home. A continuous measure of parental savings and investments is based on how much the cohort member has in savings and investments altogether.

We also account for family circumstances and resources by combining information on family structure, partner's education, and partner's class position: 1) no partner, 2) partner left education at age 16/not employed in managerial or professional occupations, 3) partner continued education after age 16/not employed in managerial and professional occupations, 4) partner left education at age 16/employed in managerial or professional occupations, 5) partner continued education after age 16/employed in 
managerial or professional occupations. To account for the wider family environment, we use a measure of parents' number of siblings (grandchild's number of aunts and uncles): 1) zero, 2) one sibling, 3) two siblings, 4) three siblings, 5) more than four siblings.

Aside from these common socioeconomic characteristics, we use parental information on their birth weight (in grams), cognitive ability, and health. Parental cognitive ability at age ten is measured with four sub-scales from the British Ability Scales: word definition, word similarities, recall of digits, and matrices (Elliott, Murray, \& Pearson, 1979). To derive general parental cognitive ability, we used principal component analysis following previous studies (Connelly \& Gayle, 2019; Schoon, 2010). Parental health is measured with a self-assessment at age 34 comprising four categories: 1) Excellent, 2) Good, 3) Fair, 4) Poor/Very Poor.

As baseline confounders (depicted as Z in Figure 2), we consider the region where grandparents lived when parents were born: North, Yorks and Humberside, East Midlands, East Anglia, South East, South West, West Midlands, North West, Wales, and Scotland. Treatment-induced mediator-outcome confounders (depicted as L in Figure 2) are measured with grandparents' income, class position, homeownership status, and self-reported health when parents were ten years old. Grandparents' income refers to total gross weekly family income when the parent was ten years old and is derived from a banded income question: 'Less than $£ 35$ per week', ' $£ 35$ to $49 £$ per week', ' $£ 50$ to $£ 99$ per week', ' $£ 100$ to $£ 149$ per week', '£150 to $£ 199$ per week', '£200 to $£ 249$ per week, 'More than $£ 250$ per week'. To use this measure as a continuous variable, we take the categories' midpoints and multiply the highest income category with the factor 1.1. The grandparent class is operationalized with NS-SEC using additional occupational coding provided by Gregg (2012). We follow the 'dominance principle' and measure the highest class position among grandparents differentiating between working class, intermediate class, and service class. Grandparents' homeownership status is measured by differentiating between owning a home (owned outright/being bought) and renting a home when the parent was ten years old. Grandparent's health is measured with a question asking whether grandparents had any severe or prolonged illness (medical, surgical, or psychiatric) or any handicap or disability since the child's fifth birthday (see Table 1 for summary statistics on all variables). 


\section{Findings}

Table 2 presents estimates for the randomized intervention analogue of the Natural Direct Effect (NDE $\left.{ }^{R}\right)$ of grandparent education on grandchildren's verbal and cognitive ability under different model specifications. Estimates in models M1-M4 are derived from a conditional mean model of the child outcomes described in equation three. These models do not allow for interactions between grandparent education and parent characteristics $\left(\beta_{5}^{T}=0\right)$. While model M1 does not include any control variables, model M2 adjusts for the baseline confounder region. Model M3 includes all parent characteristics. Model M4 additionally controls for untransformed treatment-induced confounders (L, see again Figure 2). Models M5 and M6 estimate the randomized intervention analogue of the NDE ${ }^{R}$ using a Regression-WithResiduals (RWR) approach. While M5 adjusts for residualized treatment-induced confounders $\left(L^{\perp}\right.$, see again Figure 3), M6 allows for an interaction between grandparent education and parental cognitive ability in the outcome model. Comparing M4 to M5 and M6 allows us to assess to what extent treatmentinduced confounders and interactions between grandparent and parent characteristics (in this case, G2 cognitive ability) bias the estimation of the direct effect of grandparent education on child outcomes.

Table 2 indicates that a grandparent degree is associated with an eight-point higher verbal ability for the grandchildren. This is equivalent to a difference of more than a third of the standard deviation of verbal ability (SD $=21.43)$. While the association changes little when including grandparents' region into the model, it is substantially reduced to less than one point on the verbal ability scale when adjusting for all measured parental characteristics. Accounting for treatment-induced confounders in the fourth model does not change the estimate for NDER of grandparent degree, nor does appropriately adjusting for these post-treatment confounders in the fifth model. Modeling an interaction between G1 degree and G2 cognitive ability somewhat increases the estimate of the $\operatorname{NDE}^{R}$ to more than 1.3 points on the verbal ability scale. This shows that we underestimate the direct effect of grandparent education on grandchildren's cognitive ability without allowing for heterogeneity in the grandparent effect across parental cognitive ability. Nevertheless, the estimate in model 6 is not statistically significant, and its size is small. 
Table 2. Randomized intervention analogue of the Natural Direct Effect $\left(\mathrm{NDE}^{\mathrm{R}}\right)$ of $\mathrm{G} 1$ education on $\mathrm{G} 3$ verbal $(N=1,898)$ and numerical ability $(N=1,884)$

\begin{tabular}{|c|c|c|c|c|c|c|}
\hline & $\begin{array}{l}\text { M1: } \\
\text { Bivariate }\end{array}$ & $\begin{array}{l}\mathrm{M} 2: \quad \mathrm{G} 1 \\
\text { region }(\mathrm{Z})\end{array}$ & $\begin{array}{l}\text { M3: M2 + } \\
\text { all G2 } \\
\text { variables } \\
\text { (M) }\end{array}$ & $\begin{array}{l}\text { M4: M3 + } \\
\text { treatment- } \\
\text { induced } \\
\text { confounders } \\
\text { (L) }\end{array}$ & $\begin{array}{l}\text { M5: M3 + } \\
\text { residualized } \\
\text { treatment- } \\
\text { induced } \\
\text { confounders }\left(L^{\perp}\right)\end{array}$ & $\begin{array}{l}\text { M6: M5 + G1 } \\
\text { education } x \\
\text { G2 cognitive } \\
\text { ability }\end{array}$ \\
\hline Verbal & $7.981^{* * *}$ & $7.819^{* * *}$ & 0.861 & 0.822 & 0.784 & 1.313 \\
\hline ability & (1.379) & (1.393) & (1.484) & (1.688) & (1.455) & (1.894) \\
\hline Numerical & $5.632^{* * *}$ & $5.598^{* * *}$ & 0.899 & 0.871 & 0.870 & 1.871 \\
\hline ability & $(1.126)$ & (1.167) & (1.201) & (1.331) & (1.147) & (1.343) \\
\hline
\end{tabular}

Source: British Cohort Study (BCS70); Note: M1-M4 estimated by OLS; M5-M6 estimated by Regression-withResiduals (RWR) approach and 1000 bootstrap replications; Cluster-robust standard errors in parentheses; ${ }^{*} p<0.05$, ${ }^{* *} p<0.01,{ }^{* * *} p<0.001$.

For numerical ability, we found the same patterns across the six models. The advantage for children whose grandparents have a degree equals less than six points on the age-normalized scale. This is equivalent to one-third of the standard deviation of numerical ability $(S D=16.76)$. Hence, the gross associations with grandparent education are very similar across different forms of cognitive ability (verbal, numerical). Again, the association between G1 degree and G3 cognitive ability is very much reduced when adjusting for all measured parental characteristics in the third model. Adjusting for treatment-induced confounders using an RWR approach does not make any difference to the estimate of the NDE ${ }^{R}$. As with verbal ability, we underestimate the direct effect of G1 education if we fail to account for the moderating role of parental cognitive ability in the association between grandparent education and grandchildren's numerical ability. However, the estimate is not statistically significant, and the size remains small (around $10 \%$ of the standard deviation). 
Table 3. Decomposition of $\mathrm{G} 1$ education effect on $\mathrm{G} 3$ verbal $(\mathrm{N}=1898)$ and numerical ability $(\mathrm{N}=1884)$ into direct and indirect effect via $\mathrm{G} 2$ cognitive ability (M)

$\begin{array}{lll}\text { M1: G1 region (Z) + G2 } & \text { M2: M1 + residualized } & M 3: M 2+G 1 \text { education } \\ \text { cognitive ability (M) } & \begin{array}{l}\text { treatment-induced } \\ \text { confounders }\left(L^{\perp}\right)\end{array} & x \text { G2 cognitive ability (M) } \\ & & \end{array}$

\section{Verbal ability}

$\begin{array}{cccc}A T E_{R W R}^{R} & 7.819^{* * *} & 7.819^{* * *} & 7.819^{* * *} \\ & (1.362) & (1.362) & (1.362) \\ N I E_{R W R}^{R} & 5.223^{* * *} & 4.921^{* * *} & 4.145^{* * *} \\ & (0.675) & (0.674) & (1.197)\end{array}$

\section{$\%$ explained by $\mathrm{M}$}

66.8

62.9

53.0

\section{Numerical ability}

$\begin{array}{lccc}A T E_{R W R}^{R} & 5.598^{* * *} & 5.598^{* * *} & 5.599^{* * *} \\ & (1.216) & (1.216) & 11.215) \\ N I E_{R W R}^{R} & 3.485^{* * *} & 3.275^{* * *} & 2.283^{*} \\ & (0.510) & (0.511) & 1.159)\end{array}$

Source: British Cohort Study (BCS70); Note: M1-M3 estimated by Regression-with-Residuals (RWR) approach using 1000 bootstrap replications; $A T E_{R W R}^{R}=$ randomized intervention analogue of the average total effect; $N I E_{R W R}^{R}=$ randomized intervention analogue of the natural indirect effect; Treatment-induced confounders $L^{\perp}$ include G1 class, income, homeownership, health and G2 birth weight. Cluster-robust standard errors in parentheses; ${ }^{*} p<0.05$, ${ }^{* *} p<0.01,{ }^{* * *} p<0.001$. 
Table 3 considers the mediating role of parental cognitive ability in the effect of grandparent education on grandchildren's verbal and numerical ability. The first model in Table 3 provides estimates for the randomized intervention analogue of the $\mathrm{NIE}^{R}$ via parental cognitive ability alone. The second model additionally accounts for residualized treatment-induced confounders in the outcome model. In addition to treatment-induced confounders at the G1 level, we also include the residualized G2 birth weight in the outcome model as parents' birth weight is a confounder of the effect of parental cognitive ability on children's verbal and numerical ability. All other G2 characteristics potentially mediate the link between G2 cognitive ability and G1 outcomes and, consequently, are not included in the model. The last model estimates the $\mathrm{NIE}^{\mathrm{R}}$ when including an interaction term between grandparent education and parental cognitive ability in the outcome model.

Table 3 also displays the percentage of the randomized intervention analogue of average total effect $\left(A T E^{R}=N I E^{R}+N D E^{R}\right)$ mediated by parental cognitive ability. This provides a measure of the extent to which the indirect pathway via parental cognitive ability explains the overall effect of grandparent education on grandchildren's outcomes. The first model shows that around two-thirds of the ATE of grandparent education on grandchildren's verbal and numerical ability are explained by parental cognitive ability alone. However, this model does not appropriately adjust for treatment-induced confounders and does not allow for an interaction between treatment and mediator. The second model illustrates that we would slightly overestimate the NIER via parental cognitive ability on both outcomes if we did not account for residualized treatment-induced confounders. The mediating role of $\mathrm{G} 2$ cognitive ability is further reduced when modeling an interaction between grandparent education and parental cognitive ability, particularly for numerical ability. In the last model, The ATE ${ }^{R}$ of grandparent education is explained by parental cognitive ability to $53 \%$ for verbal ability and $40.8 \%$ for numerical ability. This is a reduction of the NIE ${ }^{R}$ by $21 \%$ (verbal ability) and 35\% (numerical ability) from the first model commonly used in traditional mediation analyses. While the NDE ${ }^{R}$ would be interpreted as statistically non-significant in the first model for both outcomes, it would be considered statistically significant at the $5 \%$-level in the last model. Nevertheless, even when appropriately modeling treatment-induced confounders and allowing for a treatment-mediator interaction, parental cognitive ability is a strong mediator of the link between grandparent education and grandchildren's verbal and numerical ability.

\section{Discussion}

This paper aimed to contribute to the literature on multigenerational mobility by investigating the role of parental cognitive ability in mediating the association between grandparent education and 
grandchildren's cognitive ability. A fundamental interest in the grandparent literature is to assess whether grandparents directly affect their grandchildren's development net of any parental influences. However, parents' cognitive ability levels were largely overlooked when estimating the direct effect of grandparent resources on grandchildren's outcomes, leading to omitted variable bias at the parent level. Furthermore, we raised some methodological challenges (treatment-induced confounders; treatment-mediator interaction) that may bias the estimate for the direct effect of grandparent education on grandchildren's cognitive outcomes. To overcome these issues, we suggested focusing on the randomized intervention analogue of the Natural Direct Effect $\left(\mathrm{NDE}^{\mathrm{R}}\right)$ and a regression-with-residuals approach.

Our findings align with recent literature (e.g., Engzell et al., 2020), showing that there is only a small, if any, direct effect of grandparent education on grandchildren's verbal and numerical ability once all indirect paths through parent characteristics were disabled. While appropriately dealing with treatmentinduced confounders does not affect the estimation of the direct effect of grandparent education, we would somewhat underestimate the direct effect had we not modelled an interaction between treatment and parental cognitive ability.

Disentangling the direct and indirect pathways via parents' cognitive ability shows that this mediator alone can account for more than two-thirds (numerical ability) or half (verbal ability) of the effect of grandparent education on grandchildren's cognitive outcomes. Hence, parental levels of cognitive ability cannot be ignored when estimating the direct effect of grandparent resources on grandchildren's outcomes. Failing to account for this important parental characteristic may lead to biased conclusions about the direct effect of grandparents on grandchildren's development. Although the mediating role of parental cognitive ability is significant, our causal mediation analysis illustrates that we would overestimate the indirect effect via parental cognitive ability had we not appropriately accounted for treatment-induced confounders and a treatment-mediator interaction.

What are the lessons for the grandparent literature and the social stratification literature generally? First, reducing measurement error in socioeconomic characteristics across all generations is essential (Engzell et al., 2020), but it also vital to capture parental characteristics as much as possible to avoid omitted variable bias. While Anderson et al. (2018) found that, on average, 30 percent of the grandparent effect remains once studies accounted for parental characteristics, only 11 percent (verbal ability) and 16 percent (numerical ability) remain in our analysis once disabling all mediating pathways via parental 
characteristics. Hence, having detailed information on the parental generation is key for estimating the direct effect of grandparent resources, the target quantity of interest.

Second, the grandparent literature cannot ignore treatment-mediator interactions when estimating the direct effect of grandparent resources on grandchildren's outcomes. The literature provided evidence for the 'compensation hypothesis' (for an overview, see Anderson et al., 2018; Braun \& Stuhler, 2017; Deindl \& Tieben, 2016; Jaeger, 2012), i.e., the lower the parental resources (e.g., educational qualifications) the higher the grandparent effect. It means multiple direct and indirect effects for each value of the mediator, and findings from traditional approaches to mediation analysis cannot be meaningfully interpreted. Our analyses show that estimating the $\mathrm{NDE}^{\mathrm{R}}$ is a feasible and valuable option to capture whether grandparent resources still affect grandchildren's outcomes after deactivating any influence through parent characteristics.

Third, our findings show that cognitive ability is an essential pathway in multigenerational social reproduction and should be considered when investigating pathways between social origin and destination. While we investigated the mediating role of parental cognitive ability in grandparent effects on grandchildren, exploring the contribution of children's cognitive ability to family background differences in labor market destinations is equally important. A central question in the social mobility literature is to ask to what extent individuals' educational attainment explains class of origin differences in class destinations. However, traditional mediation analysis could be misleading if identifying direct class of origin effects and indirect effects via educational attainment is affected by collider bias. Individuals' cognitive ability (among other factors) is likely a treatment-induced mediator-outcome confounder that researchers need to appropriately model when estimating direct and indirect effects of social origin via educational attainment.

Moreover, the literature has consistently found that the influence of social class origin on social class destinations is weaker among the highly educated than among the low educated (e.g., Breen \& Jonsson, 2008; Hout, 1988). Hence, we could estimate various social origin effects depending on individuals' educational qualifications. Causal mediation analysis is a powerful tool to overcome these challenges in social mobility research and helps to quantify the pathways between social origin and labor market destinations accurately. It may therefore advance our understanding of intergenerational social reproduction processes in future research. 


\section{References}

Acharya, A., Blackwell, M., \& Sen, M. (2016). Explaining causal findings without bias: Detecting and assessing direct effects. American Political Science Review, 110(3), 512-529. https://doi.org/10.1017/S0003055416000216

Anderson, L., Sheppard, P., \& Monden, C. (2018). Grandparent effects on educational outcomes: A systematic review. Sociological Science, 5, 114-142. https://doi.org/10.15195/v5.a6

Bengtson, V. L. (2001). Beyond the nuclear family: The increasing importance of multigenerational bonds. Journal of Marriage and Family, 63(1), 1-16. https://doi.org/10.1111/j.1741-3737.2001.00001.x

Bol, T., \& Kalmijn, M. (2016). Grandparents' resources and grandchildren's schooling: Does grandparental involvement moderate the grandparent effect? Social Science Research, 55, 155-170. https://doi.org/10.1016/j.ssresearch.2015.09.011

Braun, S. T., \& Stuhler, J. (2017). The transmission of inequality across multiple generations: Testing recent theories with evidence from Germany. Economic Journal, 128(609), 576-611. https://doi.org/10.1111/ecoj.12453

Breen, R., \& Jonsson, J. O. (2008). Explaining Change in Social Fluidity: Educational Equalization and Educational Expansion in Twentieth-Century Sweden. American Journal of Sociology, 112(6), 1775-1810. https://doi.org/10.1086/508790

Breen, R. (2018). Some methodological problems in the study of multigenerational mobility. European Sociological Review, 34(6), 603-611. https://doi.org/10.1093/esr/jcy037

Butler, N., \& Bynner, J.M. 2016 University of London. Institute of Education. Centre for Longitudinal Studies. 1970 British Cohort Study: Ten-Year Follow-Up, 1980. [data collection]. 6th Edition. UK Data Service. SN: 3723, http://doi.org/10.5255/UKDA-SN-3723-7

Chamberlain, R. (2013). 1970 British Cohort Study: Birth and 22-Month Subsample, 1970-1972. [data collection]. 3rd Edition. UK Data Service. SN: 2666. http://doi.org/10.5255/UKDA-SN-3723-7

Chiang, Y. L., \& Park, H. (2015). Do grandparents matter? A multigenerational perspective on educational 
attainment in Taiwan. Social Science Research, 51, $163-173$. https://doi.org/10.1016/j.ssresearch.2014.09.013

Connelly, R., \& Gayle, V. (2019). An investigation of social class inequalities in general cognitive ability in two British birth cohorts. The British Journal of Sociology, 70 (1): 90-108. https://doi.org/10.1111/1468-4446.12343

Crawford, C., Goodman, A., \& Joyce, R. (2011). Explaining the socio-economic gradient in child outcomes: The inter-generational transmission of cognitive skills. Longitudinal and Life Course Studies, 2(1), 7793. http://dx.doi.org/10.14301/Ilcs.v2i1.143

de Coulon, A., Meschi, E., \& Vignoles, A. (2011). Parents' skills and children's cognitive and non-cognitive outcomes. Education Economics, 19(5), 451-474. https://doi.org/10.1080/09645292.2010.511829

Dearden, L., Sibieta, L., \& Sylva, K. (2011). The socio-economic gradient in early child outcomes: Evidence from the Millenium Cohort Study. Longitudinal and Life Course Studies, 2(1), 19-40. https://doi.org/10.14301/Ilcs.v2i1.140

Deindl, C., \& Tieben, N. (2016). Resources of grandparents: Educational outcomes across three generations in Europe and Israel. Journal of Marriage and Family. 79(3), 769-783. https://doi.org/10.1111/jomf.12382

Dunifon, R. E., Near, C. E., \& Ziol-Guest, K. M. (2018). Backup parents, playmates, friends: grandparents' time with grandchildren. Journal of Marriage and Family, 80(3), 752-767. https://doi.org/10.1111/jomf.12472

Elliott, C. D., Murray, D. J., \& Pearson, L. S. (1979). British Ability Scales. Slough: NFER.

Elliott, C. D., Smith, P., \& McCulloch, K. (1996). British Ability Scales Second Edition (BAS II): Administration and Scoring Manual. London: NFER-Nelson.

Elliott, C. D., Smith, P., \& McCulloch, K. (1997). British Ability Scales Second Edition (BAS II): Technical Manual. London: NFER-Nelson.

Elliott, J., \& Shepherd, P. (2006). Cohort profile: 1970 British Birth Cohort (BCS70). International Journal of Epidemiology, 35(4), 836-843. https://doi.org/10.1093/ije/dyl174 
Engzell, P., Mood, C., \& Jonsson, J. (2020). It's All about the Parents: Inequality Transmission across Three Generations in Sweden. Sociological Science, 7, 242-267. https://doi.org/10.15195/v7.a10

Erola, J., Kilpi-Jakonen, E., Prix, I., \& Lehti, H. (2018). Resource compensation from the extended Family: Grandparents, aunts, and uncles in Finland and the United States. European Sociological Review, 34(4), 348-364. https://doi.org/10.1093/esr/jcy021

Ferguson, J. L., \& Ready, D. D. (2011). Expanding notions of social reproduction: Grandparents' educational attainment and grandchildren's cognitive skills. Early Childhood Research Quarterly, 26(2), 216-226. https://doi.org/10.1016/i.ecresq.2010.10.001

Fiel, J. E. (2019). The Transmission of Multigenerational Educational Inequality. Social Forces, 97(4), 14551486. https://doi.org/10.1093/sf/soy090

Gregg, P. (2012). Occupational Coding for the National Child Development Study (1969, 1991-2008) and the 1970 British Cohort Study (1980, 2000-2008). University of London. Institute of Education.

Guryan, J., Hurst, E., \& Kearney, M. S. (2008). Parental education and parental time with children. Journal of Economic Perspectives, 22(3), 23-46. https://doi.org/10.3386/w13993

Hällsten, M., \& Pfeffer, F. T. (2017). Grand advantage: Family wealth and grandchildren's educational achievement in Sweden. American Sociological Review, 82(2), 328-360. https://doi.org/10.1177/0003122417695791

Hochguertel, S., \& Ohlsson, H. (2009). Compensatory inter vivos gifts. Journal of Applied Econometrics, 24(6), 993-1023. https://doi.org/10.1002/jae.1071

Hout, M. (1988). More Universalism, Less Structural Mobility: The American Occupational Structure in the 1980s. American Journal of Sociology, 93, 1358-1400. https://doi.org/10.1086/228904

Jaeger, M. M. (2012). The extended family and children's educational success. American Sociological Review, 77(6), 903-922. https://doi.org/10.1177/0003122412464040

Kalil, A., Ryan, R., \& Corey, M. (2012). Diverging destinies: maternal education and the developmental gradient in time with children. Demography, 49(4), 1361-1383. 
Lehti, H., Erola, J., Tanskanen, A., Lehti, H., Erola, J., \& Tanskanen, A. (2018). Tying the Extended Family Knot - Grandparents' Influence on Educational Achievement. European Sociological Review, 35(1), 29-48. https://doi.org/10.1093/esr/jcy044

Linver, M. R., Brooks-Gunn, J., \& Kohen, D. E. (2002). Family processes as pathways from income to young children's development. Developmental Psychology, 38(5), 719-734. https://doi.org/10.1037/0012$\underline{1649.38 .5 .719}$

Liu, H. (2018). Social and genetic pathways in multigenerational transmission of educational attainment. American Sociological Review, 83(2), 278-304. https://doi.org/10.1177/0003122418759651

Mare, R. D. (2011). A multigenerational view of inequality. Demography, 48(1), 1-23. https://doi.org/10.1007/s13524-011-0014-7

Sayer, L. C., Gauthier, A. H., \& Furstenberg, F. F. (2004). Educational differences in parents' time with children: Cross-national variations. Journal of Marriage and Family, 66(5), 1152-1169. https://doi.org/10.1111/j.0022-2445.2004.00084.x

Schoon, I. (2010). Childhood cognitive ability and adult academic attainment: Evidence from three British Cohort Studies. Longitudinal and Life Course Studies, 1(3), 241-258. http://dx.doi.org/10.14301/llcs.v1i3.93

Sheppard, P., \& Monden, C. (2018). The additive advantage of having educated grandfathers for children's education: Evidence from a cross-national sample in Europe. European Sociological Review, 34(4), 365-380. https://doi.org/10.1093/esr/icy026

Song, X. (2016). Diverging mobility trajectories: Grandparent effects on educational attainment in oneand two-parent families in the United States. Demography, 53(6), 1905-1932. https://doi.org/10.1007/s13524-016-0515-5

Stuhler, J. (2012). Mobility across multiple generations: The iterated regression fallacy. IZA Working Paper, 7072, 1-13. http://ftp.iza.org/dp7072.pdf

Sullivan, A., Ketende, S., \& Joshi, H. (2013). Social class and inequalities in early cognitive scores. Sociology, 47(6), 1187-1206. https://doi.org/10.1177/0038038512461861 
University of London. Institute of Education. Centre for Longitudinal Studies. (2016). 1970 British Cohort Study: Thirty-Four-Year Follow-Up, 2004-2005. [data collection]. 4th Edition. UK Data Service. SN: 5585, http://doi.org/10.5255/UKDA-SN-5585-3

VanderWeele, T. (2015). Explanation in causal inference: methods for mediation and interaction. Oxford University Press.

Wodtke, G. T., \& Zhou, X. (2020). Effect decomposition in the presence of treatment-induced confounding: A regression-with-residuals approach. Epidemiology, 31(3), 369-375. https://doi.org/10.1097/EDE.0000000000001168

Yeung, W. J., Linver, M. R., \& Brooks-gunn, J. (2002). How money matters for young children's development: Parental investment and family processes, Child Development, 73(6), 1861-1879.

Zhang, M., \& Li, Y. (2019). Family fortunes: The persisting grandparents' effects in contemporary British society. Social Science Research, 77, 179-192. https://doi.org/10.1016/i.ssresearch.2018.08.010

Zhou, X., \& Wodtke, G. T. (2019). A regression-with-residuals method for estimating controlled direct effects. Political Analysis, 27(3), 360-369. https://doi.org/10.1017/pan.2018.53 